\title{
Impact of Poor Nutrition on the Academic Performance of Grade Seven learners: A Case of Zimbabwe
}

\author{
Kudzai Chinyoka \\ Great Zimbabwe University \\ Department of Educational Foundations \\ Email: chinyokak@gmail.com \\ Doi:10.5296/ijld.v4i3.6169 URL: http://dx.doi.org/10.5296/ijld.v4i3.6169
}

\begin{abstract}
This paper examined the impact of poor nutrition on the academic performance of grade seven learners at two primary schools in Chivi, Zimbabwe. Its main objective is to identify mitigation policies and measures designed to reduce negative effects of poor nutrition on children's academic performance. Malnutrition remains one of the major obstacles to human well-being affecting all areas of a child's growth and development, including performance in the classroom. The study is grounded in Maslow's motivational and needs theory. In this study, a qualitative phenomenological case study design was used with focus group discussions, interviews and observations as data collection instruments to twelve (12) grade seven learners, three (3) headmasters and four (4) teachers, purposively sampled in Masvingo province. Findings revealed that malnutrition affected physical growth, cognitive development and it consequently impacts on academic performance, health and survival of learners. Malnutrition also deepens poverty due to increased health care costs. The study also established that hungry and undernourished grade seven learners were not able to take on physical work and sporting activities seriously, are less able to attend school and if they do, are less able to concentrate and learn. On the way forward, there is need to introduce nutritional gardens at community, school and at family levels. Addressing the root causes of malnutrition (such as food insecurity, poverty, population growth and socio-economic instability) is imperative for achieving sustained reductions in malnutrition.
\end{abstract}

Key words: Malnutrition, Poor Nutrition, Academic Performance, Nutrients, Food Insecurity, Poverty, Grade Seven

\section{Background of the study}

The EFA Global Monitoring Report (UNESCO 2011) states that more than a quarter of children below fifteen years of age in sub-Saharan Africa are underweight due to poor diet and malnutrition, making them more vulnerable to disease and less able to concentrate at school. Malnutrition is generally defined as a chronic condition which is a consequence of over- or under-consumption of any or several essential macro- or micronutrients relative to the individual's physiological and pathological requirements (Ecker and Nene 2012). Malnutrition is also a dangerous condition that develops when your body does not get enough nutrients to function properly. Poor nutrition can be caused by a lack of food or an unbalanced diet that's missing or insufficient in one or more nutrients (Chinyoka and Naidu, 2013). Children who do not consume adequate amounts of key nutrients, including calcium, potassium and vitamin $\mathrm{C}$ may be unable to work to their full potential at school (Nabarro et al. 2012). A study by Connell (2010:127) revealed that 34 percent of low birth weight children were either repeating grades or placed in special education classrooms while only 14 percent of normal birth-weight 
children experienced the same outcomes. Another research also reports elevated levels of grade repetition as a result of low birth weight due to poor nutrition (Bray et al., 2010, Duncan et al., 2008). Knowing more about what nutritional deficiencies can lead to, in terms of learning, will help families to feed their children adequately to succeed in class. This shows that nutrition is of paramount importance in the academic performance of grade seven children.

Shrestha \& Pathak (2012) as well as Brauw et al. (2012) concur that underfeeding in childhood was thought to hinder mental development solely by producing permanent structural damage to the brain. A child's brain during the first three years of life is rapidly developing through generation of neurons, synaptogenesis, axonal and dendric growth, and synaptic pruning each of which build upon each other (Orazem et al., 2007:25). Any interruption in this process, such as trauma, stress, under nutrition, or lack of nutrients can have long-term effects on the brain's structure and on the child's socio-emotional development and academic performance. Thus, research has established that poor nutrition in early life can limit long term intellectual development (Lacour \& Tissington 2011:525). Implicit to the above, children should not be exposed to malnutrition even at an early age for it has detrimental effects to their academic performance and their holistic development.

A number of studies in Latin America, Africa and the U.S reported that on intelligence tests, children with a history of malnutrition attained lower scores than children of similar social and economic status who were properly nourished (Fanzo 2012). Thus protein energy malnutrition, iron deficiency, anaemia, Vitamin A deficiency, these poverty related conditions decrease resistance to disease in general. Malnutrition therefore causes illness, brain damage, delayed physical growth, delayed development of motor skills and delayed intellectual development. In a project carried out by the Institute of Central America and Panama in 2008, children and young adults in Guatemala who had received nutritional supplements at infancy were studied to assess the influence of early diet and poverty on later intellectual development. Individuals who regularly consumed a highly nutritious supplement called Atole performed well on most tests. But the performance of those given a less nutritious supplement called fresco varied with poverty level (Ferguson et al. 2012: 453). Evidently, good nutrition early in life can help counteract the destructive effects of poverty on intellectual development. Those who consumed Atole scored significantly higher than those who received Fresco, an indication that poor nutrition in infancy can subsequently undermine the benefits of schooling. There is therefore ample evidence to support the view that early nutrition when children are already at school have strong beneficial effects on their ability to learn and conversely, poorly fed children find it difficult to concentrate at school, which provides strong support for school feeding schemes in poor countries and communities. It is against this background that this study explores the psychosocial effects of poor nutrition on the scholastic performance of grade seven learners in two primary schools in Chivi, Zimbabwe.

Despite high-levels of commitment in the context of the Millennium Development Goals (MDGs) and other initiatives, most developing countries are likely to fail in achieving their nutrition-related goals, although there are large differences in nutritional achievements across countries (Stevens et al. 2012). The lack of political commitment and action of central governments may be a critical factor (or even the main reason) for failure in reducing malnutrition, whereas in other developing countries a functional nutrition policy in place may be the driver of success (Nabarro et al., 2012).

\section{Theoretical framework}

This study is hinged on Abraham Maslow's theory of needs. Maslow proposed a theory of needs based on a hierarchical model of the basic needs at the bottom and higher needs at the top (physiological, safety, love, esteem, cognitive, aesthetic, self-actualisation and transcendence 
needs). The most fundamental and basic four layers of the pyramid contain what Maslow called deficiency needs or d-needs, the individual does not feel anything if they are met, but feels anxious if they are not met (Snowman \& Biehler 2011:79). Needs beyond the D-needs are called growth needs, being needs or B-needs. When fulfilled, they do not go away, rather they motivate further. Mwamwenda (2010) posited a hierarchy of needs based on two groupings, physiological needs and psychological needs.

The central point in Maslow's theory is that people tend to satisfy their needs systematically starting with the basic physiological needs and moving up the hierarchy. He believed that the higher level needs can only be achieved if the lower order needs have been satisfied first. For example, a hungry child is not likely to be motivated to self-actualise until her hunger is satisfied.

The Hierarchy of Needs theory remains valid today for understanding human motivation; personal growth and academic performance of grade seven learners in poverty stricken households.

\section{Purpose of the Study}

This study is important because it seeks to assess, examine and evaluate the impact of poor nutrition on the academic performance of grade seven learners in Zimbabwe, with the aim of suggesting sound measures and solutions thus minimising consequences caused by poor nutrition on the academic performance of learners.

\section{Major research Questions}

- What are the effects of malnutrition on the academic performance of grade seven learners?

- What recommendations can be made to attenuate the negative impact of poor nutrition on grade seven learners?

\section{METHODOLOGY}

\section{Research design}

This study entitled: Impact of poor nutrition on the academic performance of Grade Seven learners: A Case of Zimbabwe is a qualitative research that attempts to accumulate data regarding the impact of poor nutrition on the academic performance of grade seven learners in Zimbabwe. The study adopted a qualitative phenomenological case study design in order to explore and present the effects of poor nutrition on the academic performance of grade seven learners in two primary schools in Chivi district, Zimbabwe. Qualitative phenomenological case study approach is used to highlight the specific and to identify phenomena through how they are perceived by the actors in the situation. A case study design was developed in order to gain insights into not only what was happening to children's access to schooling, but also why events might be happening in that way (Yin 2012; White 2012). One of the advantages of this approach is that it allows the researcher to gain an understanding of social phenomena from participants' perspectives in their natural settings (McMillan and Schumacher 2010:315).

\section{Sampling}

The study was carried out in two secondary schools in Chivi district, Zimbabwe. The selection of the schools and the classes was purposefully done to ensure that the findings were authentic. The target population comprised students doing grade seven at the two primary schools and also teachers teaching these pupils. A sample of twelve grade seven learners comprising six 
males and six females as well as four teachers comprising of 2 males and 2 females and three headmasters, all males were purposively drawn.

\section{Data collection and analysis}

In addition to the intensive review of related literature, data was collected through interviews, focus group discussions and observations. During the focus group discussions with the grade seven learners, the researcher created a social environment in which group members were stimulated by one another's perceptions and ideas. This technique was believed to increase the quality and richness of data, more than one-on-one interviewing could have done (McMillan and Schumacher 2010:360). The research instruments were validated and reliability of data was ascertained.

An inductive approach to analysing the responses was undertaken to allow patterns, themes, and categories to emerge rather than being imposed prior to data collection and analysis (Patton 2012). This identification of themes provided depth to the insights about understanding the individual views of the grade seven learners and their teachers on the impact of poor nutrition on the academic performance of grade seven learners in Chivi, Zimbabwe.

\section{Ethical Considerations}

Permission to conduct the study was secured from Masvingo Provincial Education Office and Chivi district office, Zimbabwe. The researcher also secured permission from the selected school teachers; headmasters; selected grade seven learners and their parents.

The participants were informed that their involvement in the study was voluntary and that they were free to withdraw at any stage of the interviews if they were not comfortable. Participants were assured of anonymity in the research report. 


\section{Findings and Discussion}

The effects of poor nutrition on academic performance/ cognitive development can be summarised by the diagram below:

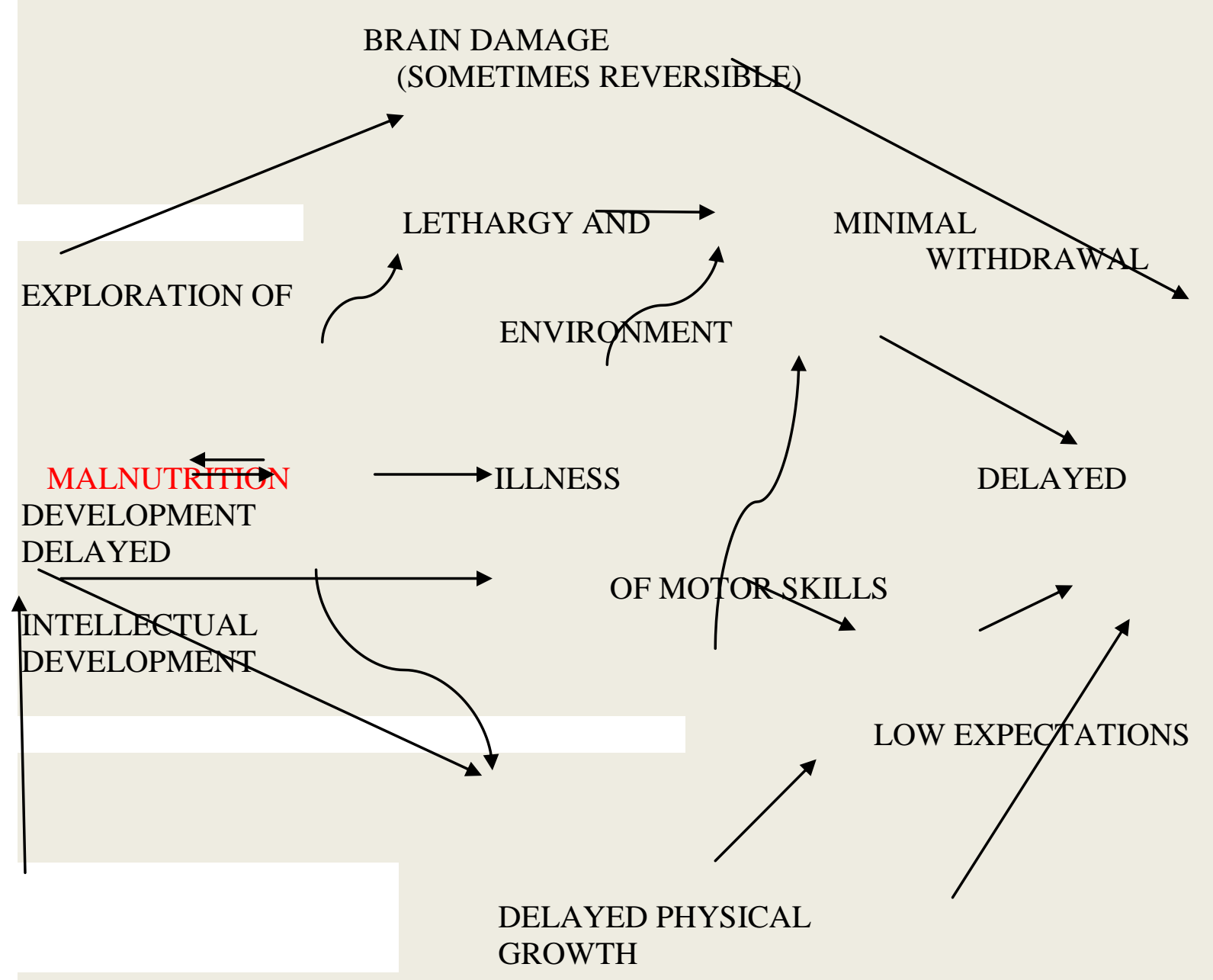

Figure 1: How malnutrition hinders cognitive development

As shown by figure 1, poverty leads to malnutrition which causes an array of psychosocial problems like illness, brain damage, delayed physical growth, delayed development of motor skills and delayed intellectual development. Malnutrition therefore alters intellectual development by interfering with overall health as well as the child's energy level, rate of motor development and rate of growth. In addition, poverty/ low economic status can exacerbate all these factors, placing impoverished children at particular risk for cognitive impairment later in life.

From the diagram above, two major themes can be derived, that is, effect on schooling/cognitive development and health challenges caused by poor nutrition. 


\section{Theme 1: Effects on schooling/cognitive development}

Malnutrition remains one of the major obstacles to human well-being and economic prosperity in developing countries (Ecker \& Nene 2012, Stevens et al., 2012). The most recent report from Save the Children stated that adults who were malnourished as children earn twenty percent less in academic performance, on average, than those who were not (Save the Children, 2012). Majority of the children interviewed highlighted that they came to school without having any breakfast. Most of the respondents narrated that their lack of food and basic meals was a contributing factor in dropping out of school. It was a major issue as they narrated that:

Sometimes we go to school without a meal. Some grade seven learners have dropped out of school because of not having any food at home. We sometimes only have one meal a day and sometimes sleep without taking in any food. We eat low calorie and less nutritious food like black tea in the morning and sadza and vegetables sometimes at lunch and /or supper.

Another child, pseudo named Tate, said they only had one meal a day while the students who participated in focus group discussions, FGD1 and FGD2 also lamented that they only had supper and breakfast. In most cases, based on the interviews with the grade seven learners, over $50 \%$ of these learners reported that they had a very small meal the previous night. Less than thirty percent (30\%) of the pupils were estimated to be taking food with them to school. From these figures, one can conclude that the majority of children in the two schools ate virtually nothing at all when they woke up in the morning and all the time when they were at school. Those who said they had all the three meals a day highlighted that the amount of food they received per meal was not always enough. It also appears that the frequency of the meals was a problem considering these statements. This was observed to have a bearing on the academic performance of children. Poor nutrition does not have to be severe in order to negatively affect child development (Benson, 2012; Stevens et al., 2012; Nabarro et al., 2012). The FAO and WHO research also demonstrate that even the slightest forms of food insecurity can affect a young child's development and learning potential (lgnowski, 2012). In support of the above, a study carried out in Kenya on adolescence who frequently did not eat breakfast or suffer from poor nutrition revealed that they generally become lethargic and stop interacting thus their learning potential is severely lowered (United Nations 2012).

Observations made by the teachers and this researcher confirmed that children from low socio-economic background who have poor nutrition end up cheating, lying and stealing, especially food from the peers or money to buy food so as to meet the basic needs. Since this behaviour is regarded by society as socially unacceptable they end up being isolated by significant others and they may develop a low self-esteem. This researcher also found out that pupils with low self-esteem are inactive, suffer from headaches and insomnia, have very high/low levels of anxiety, stress, low I.Q, mental instability, psychosocial distress as well as underachieving in their academic work. It was also observed in this study that the children who were affected by poor nutrition for a long time were more psychologically unstable than those who experienced poor nutrition within a short period of time.

Teachers interviewed assert that the majority of their students from poor backgrounds came to school without food and fail to concentrate as a result. Instead of paying attention to the teacher as she/he presents concepts to the class, the hungry learner would be busy pondering on what to do so as to get the basic needs. According to Stevens et al. (2012) a lack of a fuel-filled and healthy breakfast can cause children to have difficulties in staying awake all morning. A healthy breakfast has also been linked to fewer absences and less tardiness at school. Research findings by Miller \& Korenman (2004:238) concur that underfeeding in childhood was thought to hinder mental development solely by producing permanent, structural damage 
to the brain. Given such an argument, poor and under-nutrition tended to limit long term intellectual development of learners. Teachers interviewed Moyo; Danda and Tafo sentiments were represented by Chuma (all pseudo names) who echoed the following statements:

... When children experience food shortages and insecurity, their mental, cognitive and emotional states are altered, which can negatively affect their intellectual development. Children are often weak, drowsy in lessons and sick because of starvation. Children who walk long distances on empty stomachs fail to concentrate in school work thus negatively affecting their academic performance.

Tafo also lamented that:

Poor nutrition among grade seven learners causes them to be reserved in class, lethargy and withdrawal, a low self-concept and esteem, illness, brain damage, delayed development of motor skills and intellectual development...grade seven learners who have poor nutrition lag behind in academic performance as a result.

This also confirms the views raised by the two headmasters, $\mathrm{H} 1$ and $\mathrm{H} 2$ during interviews. In agreement, the IRIN (2011) report in Chinyoka and Naidu (2013) states that malnutrition and poor health is a large contributor to low retention and poor performance in school. Research participants posit that food insecurity and significant malnutrition levels can have direct effects on a child's performance and achievement in school and hence on their future prospects. An argument that may be easier to substantiate is that a hungry child is more likely to have lower concentration levels, a poor listening span and problems in retrieving and accessing information than her and his classmates who receive enough to eat (one of the teachers interviewed) and this may, amongst other factors, have an impact on a child's ability to perform in class. Therefore, receiving a regular breakfast, lunch and dinner leads to positive effects on a child's learning achievements (two teachers interviewed). Given the above, better nutrition and food security are therefore positively associated with improvements in schooling in all the two schools studied. It is argued that better fed children are more likely to enrol in school overall and also do so earlier than peers who do not have access to sufficient food or who are not food secure (Maslow in Mwamwenda 2010). In line with the above arguments, Moyo posited that:

... Food is a priceless teaching aid and learner motivator. Children who are well-nourished are more likely to enter school earlier, stay in school and have the ability to concentrate on lessons rather than hungry ones. Children with food security tend to participate more in class and in sporting activities.

This was reinforced by findings made by students in their two focus groups and all the other teachers and headmasters who were interviewed. The headmasters interviewed were also in concurrence with the findings. Observations made by this researcher and some teachers also confirmed the above findings. Conversely, a child whose education is threatened at an early age due to hunger is likely to have worse prospects for his/her future as an adult (Freud cited in Mwamwenda, 2010). Maslow believed that the higher level needs can only be achieved if the lower order needs have been satisfied first, thus a hungry person is not likely to be motivated to consider safety and affection until his or her hunger is satisfied. Rathus (2006:66) elaborates that, "All the needs in the hierarchy are innate to humans, but those higher in the hierarchy are weaker. They only direct action when all earlier needs have been satisfied"'. The implication is that only when people have enough to eat, and their physical safety is assured can they be motivated by a need to belong or a need for esteem. This implies that grade seven learners from a poor background will have problems in self-actualization because of hunger. It can be argued that the lack of physiological needs demoralise learners' innate need to excel in school work and hinders their full development. This to a larger extent was noted to affect the academic performance of primary children in this study.

Given the above, good nutrition is fundamental for individuals to realise both their physical, cognitive, and economic potential. It is the basis for individual and family well-being and 
human capital formation and, as such, key to economic and social development in the current generation and, even more so, for future generations (Benson, 2012; Hoddinott et al., 2012). Malnutrition lowers children's schooling performance, increases the risk of disability, morbidity, and mortality, and thus contributes to the intergenerational transmission of poverty and illness (a teacher interviewed).

It is clear, for example, from teachers, headmasters interviewed and students who participated in the two focus group discussions and interviews and also from observations, that at the two primary schools studied, because they practice hot seating, fewer children are in school after lunch than before lunch. The researcher and teachers observed that children tend to miss after lunch activities like clubs, sports and some lessons. Some teachers explained that some children often have a long way to walk home at lunch time and children are unable to find enough food to eat and therefore will be hungry hence they fail to return to school due to lack of energy to walk the distance back and spend an afternoon in school hungrily. Clearly therefore, food security has an impact on the attendance rates of children from the poorest households. On the other hand, this study also established that learners, who return to classes after the lunch break, are usually late. Children's concentration levels in class are affected when they have not had enough food to eat. They are understandably, more focused on this issue rather than their lessons (Chinyoka and Naidu 2013; Stevens et al. 2012; Cameron, 2012). Given the above, School Feeding Programme (SFP) is a good initiative and can be used to boost academic performance of poor grade seven learners.

The food instability and unpredictability of families of children from poor backgrounds gives children little interactions with peers and teachers at school and this according to Bronfenbrenner is the most destructive force in children's cognitive development (Bronfenbrenner 2008). This researcher noted that some NGOs, that is, God's Garden, Vision Trust, Christian Care and Care international were sometimes giving food hand-outs to orphans, girls and vulnerable children at the rural schools under study. Only an insignificant number of children however benefited. The researcher observed a lot of bias when food was distributed to both boys and girls at the rural school. Boys by virtue of being boys were given a big share of food. Girls were made to serve boys first and eat later. This was noted to be the trend even among families. The food hand outs were not sustainable hence poor children continued to suffer from problems of malnutrition.

The same above mentioned organisations had conducted workshops on nutritional gardens and conservation farming in order to boost crop yields in the areas where the two schools are located. They went on to provide fencing for gardens, treadle pumps or pumping water as well as inputs. However, not all families benefitted and it was a once off arrangement where beneficiaries were expected to maintain their projects. Most of the projects did not exist anymore because of a lack of inputs and maintenance for the pumps. Implicit to the above, the cycle of poverty is not easy to break. The situation reflects the circumstances discussed by grade seven learners who participated in the two focus groups, FGD1, FGD2, teachers and headmasters interviewed in this study. This will eventually translate to more poverty at family, community and national level thus perpetuating a cycle of poverty and failure among learners.

\section{Theme 2: Health challenges caused by poor nutrition}

Results from interviews with grade seven learners and the two focus group discussions established that there is a higher incidence of such conditions as asthma, respiratory infections, headaches, stomach pains, stress related ailments, poor vision, marasmus, rickets, kwashiorkor, coughs, diarrhoea, ear infections and hearing loss among children from poverty stricken households who are malnourished. Grade seven students who participated in the two 
focus group discussions (FGD1 and FGD2) stressed that the lack of nutritious food triggers an array of health problems in children, many of which can become chronic. This researcher observed that a myriad of these diseases affect the ability of children to benefit from education and to function intellectually, socially and economically later in their lives thus it can cripple a society for a generation or more.

It was also observed in this research that children who were poorly fed had a very low height for their age. Results from interviews with teachers and headmasters revealed that children experienced stunted growth because they were underfed. This confirmed findings made by lgnowski (2012); Donald et al. (2010:156); Lacour and Tissington (2011:552) who posit that children who are under fed are much more prone to the health risks and safety risks associated with malnutrition, disease, infection, and injury than are children who are not under fed. Many of these health and safety risks cause physical, cognitive, neurological or sensory problems that are likely to cause disabilities and learning difficulties (Donald et al., 2010:276), hence the children's level of attention and ability to do complex intellectual work increase with the development of the sense organs as well as the brain.

In agreement, health problems and nutrition deficits are important ways through which poverty affect children's cognitive and school related outcomes (Rusinga and Moyo 2012). Teachers and the headmasters interviewed posit that the greater incidence of health issues among lower income students lead to increased grade repetition, school absences, school dropout, tardiness rates, incidence of illness during class and high rates of undiagnosed and or untreated health problems or disabilities. This was also reinforced and supported during the interviews with grade seven learners, teachers and headmasters. Donald et al. (2010) concur with the above sentiments purporting that children who are poorly fed tend to miss school more often because of illness, a teacher, Mr Chuma said that:

...health problems among learners lead to high levels of stress and anxiety, headaches, insomnia, a low self-esteem, low I.Q, mental instability, psychosocial distress as well as underachieving in their academic work.

These issues were also highlighted by students who participated in the focus groups, FGD1 and FGD2. Contributing factors given by the respondents include financial constraints, poor nutrition, unhealthy environmental conditions, and inability to obtain appropriate health care. This study observed that such learners are usually stigmatised, labelled and looked down upon. They also develop an inferiority complex as a result. This was also reinforced and supported during the interviews with grade seven learners and the two focus group discussions when all the learners spoke about their health experiences. It should therefore be argued that poor health is detrimental to the cognitive development of learners. To worsen the plight of- learners, this researcher observed that most parents could not afford to buy medicines and pay for medical bills for their children. Teachers and headmasters also observed that some children's attendance to school was erratic because of the various illnesses observed thus negatively affecting their academic performance. In an interview, one headmaster emphasised that a health student is a productive student. This has turned into a mere lip service as most of them are failing to maintain a healthy state due, among other factors, to poor diet. Health is fast becoming a luxury which only those who afford to pay the doctors, medical bills and drugs can get. The question most people are asking now is, "Is the health and education for all by the year 2015 slogan going to become a reality or remain a distant dream" (United Nations 2012).

\section{CONCLUSION/ RECOMMENDATIONS}

On the basis of the findings of this study, recommendations were made. It is recommended that all people and stakeholders should work hard to minimise the root causes of poor 
nutrition (socio-economic instability, political unrest, land problem and the issue of international sanctions in Zimbabwe).

Nutrition support programs, such as food support programs for pregnant women, children in schools, introduction of Nutrition gardens by Non-Governmental Organisations (NGO) called God's garden who give food hand-outs to the children comprising, soya beans, soya blend porridge, cooking oil, mealie-meal and sometimes peanut butter. Such nutrition programmes have gone a long way in alleviating developmental problems in children due to poor nutrition.

The teachers need to be warm, supportive and nurturing towards learners who are psychologically unstable due to poor nutrition so as to raise their self-confidence, self-direction, self-esteem and self-image. The sense of belonging as advocated by Maslow motivates the learners to work and co-operate with peers as they engage in co-operative learning mastery of concepts is enhanced. In support, Snowman \& Biehler (2011) assert that teachers should approach their students with love, acceptance and respect and empathize with their fears, expectations and disappointments as this boosts a positive self-concept.

\section{REFERENCES}

Benson, T. 2012. Cross-sectorial coordination in the public sector: A challenge to leveraging agriculture for improving nutrition and health. In: S. Fan and R Pan-dya-Lorch (Eds.), Reshaping Agriculture for Nutrition and Health. Washington DC: International Food Policy Research Institute.

Brauw, A., Meenakshi, J. \& Gilligan, D. 2012. Introduction of beta-carotene-rich orange sweet potato in rural Uganda resulted in increased vitamin A intakes among children and women and improved vitamin A status among children. Journal of Nutrition, 142 (6): 1871-1880.

Bray R., Gooskens, I., Khan, L., Moses, S. \& Seekings, J. 2010. Growing up in the new South Africa: Childhood and adolescence in post-apartheid. Cape Town: HSRC Press.

Bronfenbrenner, U. 2008. Child development and adolescence. Chiccago: Harvard College Cameron, S. 2012. Education, urban poverty and migration: Evidence from Bangladesh and Vietnam. Working Paper 2012- 2015. UNICEF Office of Research, Florence.

Chinyoka, K. \& Naidu, N. 2013. Uncaging the Caged: Exploring the Impact of Poverty on the Academic Performance of Form Three Learners in Zimbabwe. International Journal of Educational Sciences, 6:203-213.

Connell, RW. 2010. Poverty and education. Harvard and Educational Review, 64: 125-150.

Donald, D., Lazarus, S. \& Lolwana, P. 2010. Educational Psychology in social context: Ecosystem applications in Southern Africa. Cape Town: Oxford University Press.

Duncan, DJ., Yeung, JW., Brooks-Gunn, J. \& Smith, JR. 2008. How much does child poverty affect the life chances of children? American Sociological Review, 63(4): 406-423.

Ecker, O. \& Breisinger, C. 2012. The food security system: A new conceptual framework. IFPRI Discussion Paper 1166. Washington, DC: International Food Policy Research Institute. Ecker, O. \& Nene, M. 2012. Nutrition policies in developing countries: Challenges and highlights. Policy Note 1. Washington DC, International Food Policy Research Institute.

Fanzo, J. 2012. The nutrition challenge in Sub-Saharan Africa. Human Development Report: UNDP.

Ferguson, CJ., Munoz, ME. \& Medrano, M.R. 2012. Advertising influences on young children's food choices are only marginally reduced by parental influence: A randomised controlled experiment. Journal of Pediatrics, 160 (3): 452-455.

Hoddinott, J., Rosegrant, M. \& Torero, M. 2012. Investments to reduce hunger and under-nutrition. Hunger and Malnutrition Challenge Paper. Copenhagen Consensus, 2012. 
Ignowski, EA. 2012. Two essays on food security in Zimbabwe. Master of Science in Agricultural and applied Economics in the Graduate College of the University of Illinois: Urbana, Champaign 2012.

Lacour, M. \& Tissington, LD. 2011. Educational research and reviews. Academic Journal, 7 (9): 522-527.

McMillan, JH. \& Schumacher, S. 2010. Research in education. New York: Harper Collins.

Miller, J. \& Korenman, S. 2004. Poverty and children's nutritional status in the United States. American Journal of Epidemiology, 140(3): 233-243.

Mwamwenda, TS. 2010. Educational psychology: An African perspective. Durban: Heinemann.

Nabarro, D., Menon, P., Ruel, M. \& Yosef, S. 2012. Scaling Up Nutrition: A global movement to accelerate progress in reducing maternal and child under-nutrition. Brief 9. In: J. Linn. (ed.).

Orazem, P., Glewwe, P. \& Patrinos, H. 2007. The benefits and costs of alternative strategies to improve educational outcomes. Working Paper No. 07028. Ames, Iowa: Iowa State University.

Patton, MQ. 2012. Qualitative evaluation and research methods. (7th ed.). Thousand Oaks, CA: Sage Publications, Inc.

Rathus, SA. 2006. Childhood: Voyages in development. California: Thomson Wadsworth.

Rusinga, O. \& Moyo, S. 2012. Determinants of child malnutrition in Changazi Ward in Chimanimani District, Zimbabwe. Journal of Emerging Trends in Educational Research and Policy Studies. (JETERAPS). 3(3): 14-19.

Save the Children. 2012. A life free from hunger: Tackling malnutrition. New York: United Nations.

Shrestha, I. \& Pathak, L. 2012. A Review of the National Health Policy 1991. Katmandu: Ministry of Health and Population.

Snowman, J. \& Biehler, R. 2011. Psychology applied to teaching. Boston: Houghton Mifflin.

Stevens, G., Finucane, M., Paciorek, C., Flaxman, S., White, R., Donner, A. \& Ezzati, M. 2012. Trends in mild, moderate, and severe stunting and underweight, and progress towards MDG 1 in 141 developing countries: A systematic analysis of population representative data. Lancet, 380(7):824-834.

United Nations. 2012. The Millennium Development Goals Report. New York: United Nations.

UNESCO. 2011. EFA Global Monitoring Report 2011: The hidden crisis: Armed conflict. Paris: UNESCO. 
White, CJ. 2012. Research methods and techniques. New York: Harper Collins College.

Yin, RK. 2012. Case study research: design and methods. (7th ed.) New Delhi: SAGE Publication. 